\title{
Enzymatic Decolorization of Textile Dyeing Effluents
}

\author{
Elias Abadulla, Karl-Heinz Robra, and Georg M. GÜbitz \\ Department of Environmental Biotechnology, Graz University of Technology, A-8010 Graz, Austria \\ Luisa M. Silva and Artur Cavaco-Paulo \\ Department of Textile Engineering, University of Minho, 4800 Guimarães, Portugal
}

\begin{abstract}
Commercial azo, triarylmethane, antraquinonic, and indigoid textile dyes are efficiently decolorized with enzyme preparations from Pleurotus ostreatus, Schizophyllum commune, Neurospora crassa, Polyporus sp., Sclerotium rolfsii, Trametes villosa, and Myceliophtora thermophila. The nature of substituents on the dyes' benzene rings influences enzyme activity, and hydroxyl and amino groups enhance decolorization. The presence of lignin peroxidase and/or manganese peroxidase in addition to laccase ( $P$. ostreatus, $S$. commune, $S$. rolfsii, $N$. crassa) increases decolorization by up to $25 \%$. The effect of textile dyeing auxiliaries depends on the individual enzymes. Polyporus sp. and $T$. villosa are inhibited up to $20 \%$ by copper and iron chelating agents and anionic detergents, while the $S$. commune enzymes lose up to $70 \%$ of their activity.
\end{abstract}

Large amounts of dyestuffs are used for textile dyeing as well as for other industrial applications. As a characteristic of the textile processing industry, a wide range of structurally diverse dyes can be used in a single factory, and therefore effluents from the industry are extremely variable in composition. This underlines the need for a largely unspecific process for treating textile waste water. It is known that $90 \%$ of reactive dyes entering activated sludge sewage treatment plants will pass through unchanged and be discharged in to rivers [29]. Interest in the pollution potential of textile dyes has been primarily prompted by concern over their possible toxicity and carcinogenity. Not all dyes currently used can be degraded or removed with physical and chemical processes, and sometimes the degradation products are more toxic [30]. Several combined anaerobic and aerobic microbial processes using adapted mixed populations are believed to enhance the degradation of textile dyes [4, $20]$, but under anaerobic conditions, azo reductases usually cleave azo dyes into the corresponding amines, many of which are mutgenic or carcinogenic [7, 9]. Furthermore, azo reductases have been shown to be very specific enzymes, thus cleaving only the azo bonds of selected dyes $[35,36]$. In contrast, the phenoloxidaseslignin peroxidase (ligninase, LiP), manganese peroxidase $(\mathrm{MnP})$, and laccase - act more unspecifically on aromatic rings and thus have the potential to degrade a wide range of aromatic structures [31].
Lignin peroxidase (ligninase, LiP), manganese peroxidase $(\mathrm{MnP})$, and laccase are involved in the biodegradation of lignins, which are complex polyaromatic polymers constituting the main noncarbohydrate component in wood and are among the most abundant groups of biopolymers in the biosphere. A great number of whiterot fungi have been reported to produce the ligin-degrading enzymes $\mathrm{LiP}, \mathrm{MnP}$, and laccase, or at least one of these enzymes [14, 15, 33]. Manganese peroxidase (EC 1.11.1.13; Mn (II): hydrogen peroxide oxidoreductase) and ligninase (EC 1.11.1.14; diarylpropane: oxygen, hydrogen peroxide oxidoreductase) belong to the class of peroxidases that oxidize their substrates by two consecutive one-electron oxidation steps with intermediate cation radical formation. While MnP only attack phenolic substrates using $\mathrm{Mn}^{2+} / \mathrm{Mn}^{3+}$ as an intermediate redox couple, LiP with a higher redox potential prefers nonphenolic methoxy-substituted lignin subunits as substrates [33].

Laccases (benzenediol: oxygen oxidoreductase, EC 1.10.3.2) have very broad substrate specificity with respect to the electron donor. They catalyze the removal of a hydrogen atom from the hydroxyl group of ortho- and para-substituted mono- and poly-phenolic substrates and from aromatic amines by one-electron abstraction, to form free radicals capable of undergoing further depolymerization, repolymerization, demethylation, or quinone formation [18]. 
Using laccases and manganese peroxidases for pulp bleaching and effluent treatment has gained considerable interest in the last few years, and several new processes have been patented [18]. Laccases can be used on both chlorolignins and phenolic compounds of pulp mill effluents [3]. The enzymes render phenolic compounds less toxic by means of polymerization reactions and crosscoupling of pollutant phenols with naturally occurring phenols [21]. Several processes using laccases as well as laccases immobilized on activated carbon have been developed for phenolic effluent treatment $[5,12]$. In this study we assess the potential of phenol oxidases from the fungi Pleurotus ostreatus, Schizophyllum commune, Neurospora crassa, Polyporus sp., S. rolfsii, Trametes villosa, and Myceliophtora thermophila to decolorize textile dyes, taking into account the influence of dyeing auxiliaries.

\section{Experimental}

Veratryl alcohol, sodium tartrate, sodium malonate, 2,6-dimethoxyphenol (DMP), and manganese(II)sulfate came from Sigma; all other chemicals were from Merck. Complex carbon sources for the cultivation of fungi such as wheat bran flakes, potato starch, malt extract, dextrose, and sucrose were obtained locally. The dyes C.I. Basic Violet 3, Basic Red 9 Base, Acid Violet 17, Acid Blue 74, and Acid Orange 5 came from Sigma; Reactive Blue 221 and Disperse Red 60 came from Sumitomo Chemicals; Reactive Black 5, Direct Blue 71, and Acid Blue 74 came from Ciba; and Reactive Blue 19 came from Höchst (for dye structures see Figure 1). All commercial textile dyeing auxiliaries came from Ciba.

Laccase preparations from Trametes villosa and $M y$ celiophtora thermophila were kindly provided by NovoNordisk. Pleurotus ostreatus (ATCC 9427), Schizophyllum commune (BT 2115), S. rolfsii (ATCC 200224), Neurospora crassa (DSM 1258), and Polyporus sp. H7 (BT 2313) were cultivated at $30^{\circ} \mathrm{C}$ in $300 \mathrm{ml}$ Erlenmeyer flasks on a rotary shaker $(150 \mathrm{rpm})$ containing $100 \mathrm{ml}$ media as described previously for $P$. ostreatus [27], $S$. commune [22], S. rolfsii [19], N. crassa [16], and Polyporus sp. [17]. Cultures were harvested after 8 days $(P$. ostreatus), 7 days (S. commune), 14 days $(S$. rolfsii $), 6$ days ( $N$. crassa), and 7 days (Polyporus sp.), respectively, filtered and centrifuged, and the clear supernatant was used for the enzyme activity assays and the decolorization experiments.

Laccase (benzenediol : oxygen oxidoreductase, EC 1.10.3.2) and manganese peroxidase (MnP, EC 1.11.1.13; Mn (II): hydrogen peroxide oxidoreductase) activities were determined using 2,6-dimetoxyphenol (DMP) as a substrate as described earlier [13]. The reac- tion mixture contained $50 \mathrm{mmol}$ sodium malonate $(\mathrm{pH}$ 4.5), $1 \mathrm{mmol}$ DMP, $1 \mathrm{mmol} \mathrm{MnSO}_{4}$, and $700 \mu \mathrm{l}$ sample in a total volume of $1 \mathrm{ml}$. The formation of an orange/ brownish dimer was followed spectrophotometrically at $468 \mathrm{~nm}$ (laccase activity). MnP activity equaled the increased activity after adding $0.4 \mathrm{mmol}$ hydrogen peroxide to the reaction mixture, and was corrected for laccase activity. Lignin peroxidase (LiP, EC 1.11.1.14; diarylpropane : oxygen, hydrogen peroxide oxidoreductase) activity was determined spectrophotometrically (310 nm) as the $\mathrm{H}_{2} \mathrm{O}_{2}$-dependent oxidation of veratryl alcohol to veratrylaldehyde in a reaction mixture $(1 \mathrm{ml})$ containing $50 \mathrm{mmol}$ sodium tartarate $(\mathrm{pH} 2.5), 2 \mathrm{mmol}$ veratryl alcohol, $4 \mathrm{mmol} \mathrm{H}_{2} \mathrm{O}_{2}$, and $500 \mu \mathrm{l}$ culture filtrate as described earlier [32].

For the decolorization experiments, typically $0.5 \mathrm{ml}$ dye (250 $\mathrm{mg} \mathrm{l}^{-1}$ final concentration), $0.5 \mathrm{ml}$ enzyme preparation (diluted to give $0.1 \mathrm{nkat}^{-1}$ final laccase activity), and $3.0 \mathrm{ml}$ buffer $(0.1 \mathrm{M}$ sodium acetate, $\mathrm{pH}$ 5.0) were incubated on a rotary shaker at $50^{\circ} \mathrm{C}$ for 5 hours. Decolorization was followed spectrophotometrically at the maximum absorbance of each dye, and concentrations were calculated from calibration curves recorded at those conditions. The decrease in absorbance was continuously recorded, and the values were taken after 5 hours from trend curves. The effect of commercial dyeing additives (Ciba) and salts on enzymatic decolorization was determined analogously (added to $3 \mathrm{ml}$ of the buffer) in concentrations of 1,3 , and $5 \mathrm{~g} \mathrm{l}^{-1}$ and $0.1,0.5$, 1 , and $2 M$, respectively. Calibration curves were recorded separately for all additive concentrations. All experiments were done in triplicate using heat inactivated enzyme preparations as controls.

\section{Result and Discussion}

Enzyme preparations from the fungi Pleurotus ostreatus, Schizophyllum commune, Sclerotium rolfsii, Neurospora crassa, Polyporus sp., Trametes villosa, and Myceliophtora thermophila were able to decolorize triarylmethane, azo, antraquinone, indigo, and metal chelate dyes. In all preparations, laccase was the predominant enzyme, but lignin peroxidase and/or manganese peroxidase were also present in the case of $S$. commune, $S$. rolfsii, N. crassa, and Polyporus sp. (Table I). Of the three temperature settings $\left(35,50\right.$, and $\left.65^{\circ} \mathrm{C}\right)$ and three $\mathrm{pH}$ settings ( $\mathrm{pH} 5.0,6.5,7.5$ ), all enzyme preparations were most active at $50^{\circ} \mathrm{C}$ and $\mathrm{pH} 5.0$. Initial decolorization efficiencies depended on the source of the enzymes and the substrate (dye) used (Figure 1). Of the triarylmethane dyes, Basic Violet 3 was the preferred substrate for most enzymes. Thus, most likely unsubstituted hydroxyl or amino groups on the aromatic rings, which are 


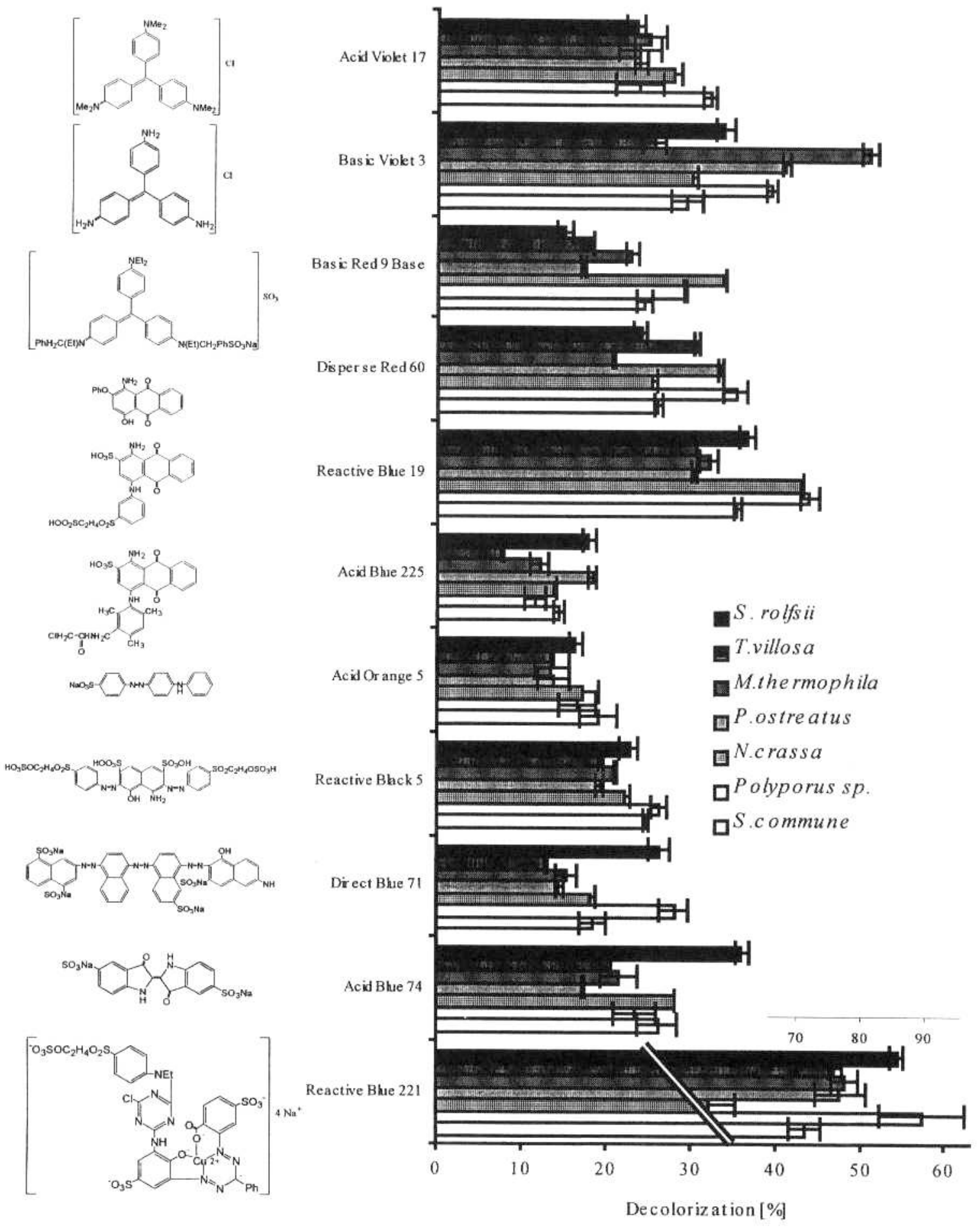

Figure 1. Enzymatic decolorization of textile dyes by enzyme preparations from $P$. ostreatus, S. commune, S. rolfsii. $N$. crassa, Polyporus sp., T. villosa, and $M$. thermophila.

missing on Acid Violet 17 and Basic Red 9 Base, were beneficial for the initial attack by phenol oxidases. These results parallel previous findings on Phanerochaete chrysosporium LiP and MnP [28], and they are in agreement with the general catalytic mechanism of laccases, which catalyze the abstraction of a hydrogen atom from 
TABLE I Ratio of laccase activity to manganese peroxidase (MnP) and lignin peroxidase (LiP) activities (nkat $\mathrm{ml}^{-1}$ ) in various enzyme preparations (laccase activity expressed as $100 \%$ ).

\begin{tabular}{lccl}
\hline Enzyme preparation & Laccase & $:$ MnP & $:$ LiP \\
\hline N. crassa & 100 & $: 32.3$ & $: 27.5$ \\
S. rolfsii & 100 & $: 20.2$ & $: 0.5$ \\
S. commune & 100 & $: 13.9$ & $: 19.2$ \\
Polyporus sp. & 100 & $: 19.0$ & $: 0.8$ \\
P. ostreatus & 100 & $: 2.68$ & $: 5.01$ \\
T. villosa & 100 & $: 0.0$ & $: 0.0$ \\
M. thermophila & 100 & $: 0.0$ & $: 0.0$ \\
\hline
\end{tabular}

the hydroxyl group of mono- and poly-phenolic substrates and from aromatic amines [31]. Similarly, the azo dye Acid Orange 5 degraded to a lesser extent than Direct Blue 71 and Reactive Black 5.

The nature of substituents on the aromatic ring has been shown to influence enzymatic oxidation. Electron donating methyl and methoxy substituents seemed to enhance enzymatic degradation of azophenols, while electron withdrawing chloro, fluoro, and nitro substituents inhibited oxidation by a laccase from Pyricularia oryzae and $\mathrm{MnP}$ from Phanerochaete chrysosporium [7, 28].

For the degradation of antraquinoid dyes, we did not observe any such general trend. However, Disperse Red 60 is not completely soluble in water, and so the results must not be directly compared with the other dyes. The presence of $\mathrm{MnP}$ and/or $\mathrm{LiP}$ in addition to laccase in the $S$. commune, S. rolfsii, Polyprous sp., and $N$. crassa enzyme preparations had a significant, positive effect on the degree of decolorization (up to $25 \%$ higher) of all azo dyes, the indigoid dye Acid Blue 74, Reactive Blue 19 (antraquinoid dye), and Basic Red 9 Base (triarylmethane dye). Previously, purified lignin peroxidases have been shown to degrade Reactive Blue 19 and other antraquinonic compounds, while $\mathrm{MnP}$ did not seem to be responsible for dye degradation [25]. Other authors have found that its higher oxidation potential allowed $\mathrm{LiP}$ to degrade model azo dyes with fluoro substituents on the phenolic ring, which $\mathrm{MnP}$ did not cleave [28]. However, a combination of LiP and other oxidative enzymes from Phanerochaete chrysosporium seemed to be responsible for degrading the azo compounds [11].

We tested various salts and textile dyeing auxiliaries (Ciba), which are usually applied in combination with textile dyes, for potential inhibitory effects on enzymes. We chose C.I. Acid Orange 5 and T. villosa. Polyporus sp., and $S$. commune for these experiments. Both sodium acetate and sodium chloride at high concentrations decreased the decolorization efficiency by up to $80 \%$ ( $2 \mathrm{M}$ $\mathrm{NaCl}$ ) and even led to partial precipitation of proteins (data not shown). This effect most likely resulted from both inactivation and precipitation of enzymes caused by increased surface tension and hydrophobic interaction. Cibacel DBC, which is used for iron and copper inactivation during textile dyeing, significantly (up to $70 \%$ ), inhibited all enzymes (Figure 2). Laccases belong to the class of blue oxidases typically containing four copper atoms per polypeptide chain distributed in three different copper binding sites [23] or one copper, one iron, and two zinc atoms per protein molecule $[26,34]$. All of these copper ions are apparently involved in the catalytic mechanism. Thus, it is obvious that chelation of copper and iron can inactivate this class of enzymes.

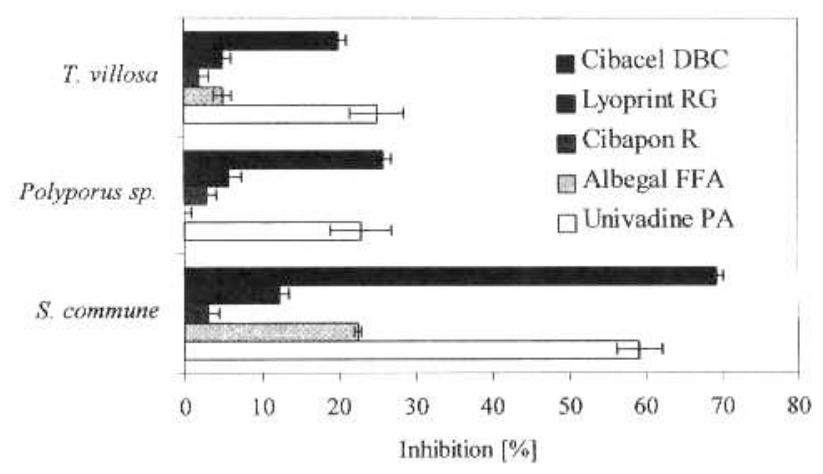

FIGURE 2. Inhibition of C.1. Acid Orange 5 decolorizing enzymes by dyeing auxiliaries.

Anionic detergents (Univadine PA) and cationic agents such as N-tetraalkylammoniumhalogenids (Tinegal MR) seemed to partially denaturate proteins (enzymes) responsible for decolorization. Also migration and penetration auxiliaries (Albegal SET) inhibited the enzymes, while soaping agents (Cibapon R), wetting agents (Albegal FFA, alkylarylpolyglycolethersulfate; Albegal FFC, alkylarylethoxylate) did not show any significant effect. As shown for $S$. commune, Polyporus sp., and $T$. villosa (Figure 2), the individual enzyme preparations were inactivated to a different extent. While Polyporus sp. and T. villosa were inhibited up to $20 \%$ by additives $\left(3 \mathrm{~g} \mathrm{I}^{-1}\right)$, the $S$. commune enzymes lost up to $70 \%$ of their activity. Thus, knowledge not only about substrate specificities but also about the effect of auxiliaries is important in selecting suitable enzymes for dye decolorization under industrial conditions.

Previously, various colored industrial effluents have been treated using immobilized bacteria or fungi, including some strains examined in our study $[1,24]$. The white rot fungus $S$. commune has been used for degrading pulp mill effluents [2], $N$. crassa has been found to degrade azo compounds $[10]$, and $P$. ostreatus has been 
shown to mineralize polycyclic aromatic hydrocarbons [6]. However, the microorganisms were cultivated under physiological conditions and had to be supplemented with nutrients not present in the effluents. Using enzymes instead of whole organisms would allow treatment of effluents with varying compositions under industrial conditions (higher temperatures and $\mathrm{pH}$, etc.). Furthermore, bacterial azo reductases produce aromatic amines, many of which are carcinogenic, while laccases and LiP have been shown to degrade azo bonds to nitrogen [7, 8].

\section{Conclusions}

In this study we have shown that enzyme preparations from Pleurotus ostreatus, Schizophyllum commune, Sclerotium rolfsii, Neurospora crassa, Polyporus sp., Trametes villosa, and Myceliophtora thermophila efficiently decolorized a variety of structurally different dyes. However, initial reaction rates depend on the individual enzymes (laccase, LiP, and MnP) in the preparations. Some dyeing additives dramatically lower decolorization rates. Thus, the effect of dyeing auxiliaries on enzyme activity must be considered when evaluating new enzymes and processes. Future investigations should focus on the immobilization of selected enzymes to form the base for industrial application of enzymatic decolorization.

\section{ACKNOWLEDGMENTS}

We wish to thank the Austrian Academic Exchange Service (ÖAD) for supporting E. Abadulla, the European Communities (Leonardo da Vinci program) for scholarship support of L. M. Silva and J. Andreaus, and B. Klug for valuable discussions.

\section{Literature Cited}

1. Banat, 1. M., Nigam, P., Singh, D., and Marchant, R., Microbial Decolorization of Textile Dye Containing Effluents, A Review, Biores. Technol. 58, 217-227 (1996).

2. Belsare, D. K., and Prasad, D. Y., Decolorization of Effluent from the Bagasse-Based Pulp Mills by White-Rot Fungus, Schizophyllum Commune, Appl. Microbiol. Biotechnol. 28, 301-304 (1988).

3. Bollag, J. M., and Leonowicz, A., Comparative Studies of Extracellular Fungal Laccases, Appl. Environ. Microbiol. 48, $849-854$ (1984)

4. Bortone, G., Effects of an Anaerobic Zone in a Textile Wastewater Treatment Plant, Water.Sci. Technol. 32, 133 140 (1995).

5. Call, H. P., and Mucke, I., Process Development and Mechanisms in the Mediated Bleaching of Pulps by Laccase, Abstr. Pap. Am. Chem. Soc. 211, 147 (1996).

6. Cerniglia, C. E., Mineralization of Polycyclic Aromatic
Hydrocarbons by the White Rot Fungus Pleurotus ostreatus., Appl. Environ. Microbiol. 62, 292-295 (1996).

7. Chivukula, M., and Renganathan, V., Phenolic Azo Dye Oxidation by Laccase from Pyricularia Oryzae, Appl. Environ. Microbiol. 61, 4374-4377 (1995).

8. Chivukula, M., Spadaro, J. T., and Renganathan, V., Lignin Peroxidase-Catalyzed Oxidation of Sulfonated Azo Dyes Generates Novel Sulfophenyl Hydroperoxides, Biochemistry-USA 34, 7765-7772 (1995).

9. Chung, K. T., and Stevens, S. E., Degradation of Azo Dyes by Environmental Microorganisms and Helminths, Environ. Toxicol. Chem. 12, 2121-2132 (1993).

10. Corso, C. R., Deangelis, D. F., Deoliveira, J. E., and Kiyan, C., Interaction Between the Diazo Dye, Vermelho Reanil P8B, and Neurospora Crassa Strain 74A, Eur. .J. Appl. Microbiol. Biotechnol. 13, 64-66 (1981).

11. Cripps, C., Bumpus, J. A., and Aust, S. D., Biodegradation of Azo and Heterocyclic Dyes by Phanerochaete chrysosporium, Appl. Environ. Microbiol. 56, 1114-1118 (1990).

12. Davis, S., and Burns, R. G., Covalent Immobilization of Laccase on Activated Carbon for Phenolic Effluent Treatment, Appl. Microbiol. Biotechnol. 37, 474-479 (1992).

13. de Jong, E., de Vries, F. P., Field, J. A., Van der Zwan, R. P., and de Bont, J. A. M., Isolation and Screening of Basidiomycetes with High Peroxidative Activity, $\mathrm{Mycol}$. Res. 96, 1098-1104 (1992).

14. Dey, S., Maiti, T. K., and Bhattacharyya, B. C., Production of Some Extracellular Enzymes by a Lignin Peroxidase Producing Brown Rot Fungus Polyporus ostreiformis and its Comparative Abilities for Lignin Degradation and Dye Decolorization, Appl. Environ. Microbiol. 60, 4216-4218 (1994).

15. Eggert, C., Temp, U., and Eriksson, K. E., Laccase Producing White Rot Fungus Lacking Lignin Peroxidase and Manganese Peroxidase, Role of Laccase in Lignin Biodegradation. ACS Symp. Ser. 655, 130-150 (1996).

16. Froehner, S. C., and Eriksson, K. E., Purification and Properties of Neurospora crassa Laccase, I. Bacteriol. 120, $458-465$ (1974).

17. Goncalves, M. L., and Steiner, W., Purification and Characterization of Laccase from a Newly Isolated WoodDecaying Fungus, ACS Symp. Ser. 655, 258-266 (1996).

18. Goncalves, M. L., and Steiner, W., Use of Laccase for Bleaching of Pulps and Treatment of Effluents, ACS Symp. Ser. 655, 197-206 (1996).

19. Gübitz, G. M., and Steiner, W., Simultaneous Production of Xylanase and Mannanase by Several Hemicellulolytic Fungi, ACS Symp. Ser. 618, 319-331 (1995).

20. Haug, W., Schmidt, A., Nortemann, B., Hempel, D. C., Stolz, A., and Knackmuss, H. J., Mineralization of the Sulfonated Azo Dye Mordant Yellow 3 by a 6-Aminonaphthalene-2-Sulfonate Degrading Bacterial Consortium, Appl. Environ. Microbiol. 57, 3144-3149 (1991).

21. Huttermann, A., Haars, A., and Herche, C., Polymerization of Water Insoluble Lignins by Fomes annosus, Holzforschung 34, 64-66 (1980).

22. Leonard, T. J., and Phillips, L. E., Study of Phenoloxidase 
Activity During the Reproductive Cycle in Schizophyllum commune, Bacteriology 114, 7-10 (1973).

23. Mayer, A. M., and Harel, E., Polyphenol Oxidases in Plants, Phytochemistry 18, 193-215 (1979).

24. Nigam, P., and Marchant, R., Selection of a Substratum for Composing Biofilm System of a Textile Effluent Decolorizing Bacteria, Biotechnol. Lett, 17, 993-996 (1995).

25. Ollikka, P., Alhonmaki, K., Leppanen, V. M., Glumoff, T. Raijola, T., and Suominen, I., Decolorization of Azo, Triphenyl Methane, Heterocyclic, and Polymeric Dyes by Lignin Peroxidase Isoenzymes from Phanerochaete chrysosporium, Appl. Environ. Microbiol. 59, 4010-4016 (1993).

26. Palmieri, G., Giardina, P., Bianco, C., Scaloni, A., Capasso, A., and Sannia, G., A Novel White Laccase from Pleurotus ostreatus, J. Biol. Chem. 272, 31301-31307 (1997).

27. Palmieri, G., Giardina, P., Marzullo, L., et al., Stability and Activity of a Phenol Oxidase from the Ligninolytic Fungus Pleurotus Ostreatus, Appl. Microbiol. Biotechnol. 39, 632636 (1993).

28. Pastigrigsby, M. B., Paszczynski, A., Goszczynski, S., Crawford, D. L., and Crawford, R. L., Influence of Aromatic Substitution Patterns on Azo Dye Degradability by Streptomyces sp. and Phanerochaete chrysosporium, Appl. Environ. Microbiol. 58, 3605-3613 (1992).

29. Pierce, J., Colour in Textile Effluents-The Origins of the Problem, J. Soc. Dyers Colour. 110, 131-134 (1994).
30. Spadaro, J. T., Lorne, I., and Renganathan, V., Hydroxyl Radical Mediated Degradation of Azo Dyes: Evidence for Benzene Generation, Environ. Sci. Technol. 28, 13891393 (1994)

31. Thurston, C. F., The Structure and Function of Fungal Laccases, Microbiology 140, 19-26 (1994).

32. Tien, M., and Kirk, T. K., LiP of Phanerochaete chrysosporium, Meth. Enzymol. 161B, 238-248 (1988).

33. Tuor, U., Winterhalter, K., and Fiechter, A., Enzymes of White Rot Fungi Involved in Lignin Degradation and Ecological Determinants for Wood Decay, J. Biotechnol. 41, 1-17 (1995)

34. Yaropolov, A. L., Skorobogatko, O. V., Vartanov, S. S., and Varfolomeyev, S. D., Laccase: Properties, Catalytic Mechanism, and Applicability, Appl. Biochem. Biotechnol. 49, 257-280 (1994).

35. Zimmermann, T., Gasser, F., Kulla, H. G., and Leisinger, T., Comparison of Two Bacterial Azoreductases Acquired During Adaptation to Growth on Azo Dyes, Arch. Microbiol. 138, 37-43 (1984).

36. Zimmermann, T., Kulla, H. G., and Leisinger, T., Properties of Purified Orange II Azoreductase, The Enzyme Initiating Azo Dye Degradation by Pseudomonas KF46, Eur. J. Biochem. 129, 197-203 (1982).

Manuscript received November 2, 1998; accepted April 9, 1999 